\title{
A BASIC STUDY ON AMBIENT CONTRAST OF A PC DISPLAY FOR OUTDOOR USE
}

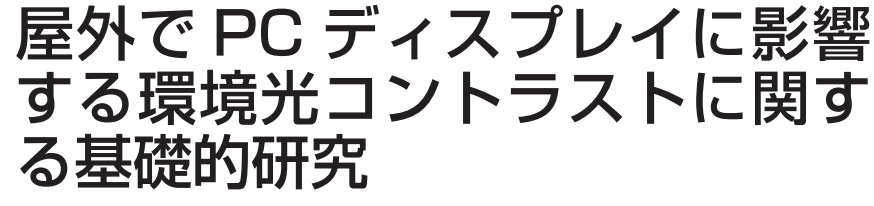

\section{Tomohiro FUKUDA - * 1}

Keywords:

Display for outdoor use, Luminance, Contrast ratio, Viewing angle, Ambient environment

キーワード :

屋外でのディスプレイ利用, 輝度, コントラスト比, 視野角, 周囲環境

\section{福田知弘 — * 1}

The outdoor use of digital tools such as AR is anticipated, but there is a problem that the content is hard to see when a normal PC display is used. In this study, to clarify the reason for this, luminance, the contrast ratio, and the viewing angle of a display designed for outdoor use were measured according to each step of 16 luminance settings in a darkroom and outdoors. Two methods of obtaining stable data of display luminance were considered, namely construction of a pilot machine which can make artificial lighting with stable environment and a computer simulation.

\section{Introduction}

Digital tools for multi-media purposes including AR (Augmented Reality) or MR (Mixed Reality) are expected to be widely used outdoors. Many papers have reported on digital tools used outdoors 1) 2) 3) 4) 5) 6). However, in general, the medium of paper is used in design studies and by tour guides due to the various problems that digital tools have. In this study, among the various problems affecting digital tools, the problem of the display is targeted. In general, the display is not easy to see outdoors due to the influence of outside light (Figure 1).

Digital tools used outside by individuals, such as cellular phones, PDAs or HMDs (Head Mounted Displays), were not the target of this study. Instead the focus was on digital tools with which a number of people can share information. It is also not suitable to use a projector instead of a display because in this research it is assumed that digital tools would be used while moving around outdoors. The papers presented so far have described the feature development of the digital tools but have not considered the problem of ease of viewing the display outdoors.

To solve the problem that the display is not easy to see outdoors is a major goal, and one approach is to manufacture a bright display where contents can be seen outdoors. Another approach is to explore the reasons that the screen contents are not seen easily outdoors, and to collect basic data which is lacking for the study of how to improvement the display. In the presented paper ${ }^{7)}$, a problem of the developed MR system was shown, namely that the display is hard to see outdoors because of the influence of the outside light. To grasp the problem quantitatively, three displays were measured. In the other presented paper ${ }^{8)}$, five displays were assessed by using a luminance meter, and three aspects, namely luminance, the contrast ratio, and the viewing angle of each display were measured in a darkroom and outdoors. To decrease the various factors affecting luminance measurement outdoors, the illuminance change outdoors, the influence of sunlight, and the influence of the ambient environment were considered.

However, these were preliminary studies and further research to obtain data more stably is needed. A function to change the brightness of the display is usually available in note PCs. Can the aspect that ambient light

'1 Assoc. Prof., Division of Sustainable Energy and Environmental Engineering, Graduate School of Engineering, Osaka Univ., Dr. Eng.
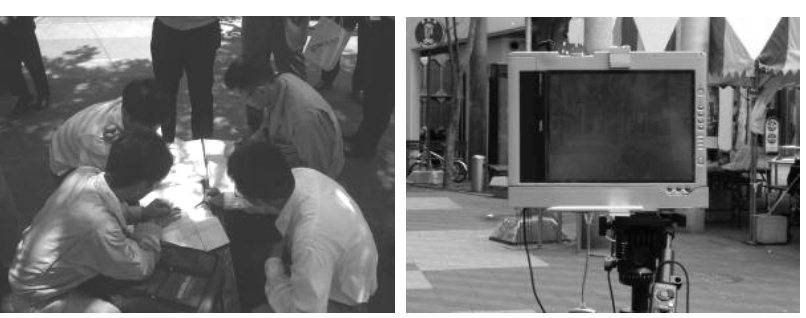

Figure 1. Sharing information outdoors using paper (left); State of display outdoors (right).

outdoors influences the display be understood by measuring the ambient contrast corresponding to the degree of change in the brightness of the display by using a note PC? No study on the change in brightness has yet been reported considering the degree of change in the brightness of the display.

This research aimed at the collection of basic data concerning the brightness of the display in the darkroom and outdoors. The research method was as follows. First of all, three aspects of the display used for evaluation were described. Next, the display of a note $\mathrm{PC}^{9)}$ for which use outdoors is assumed was measured. The brightness of the PC display could be adjusted in 16 steps, and each of these was set and the brightness was then measured in the darkroom and outdoors. Moreover, two methods of obtaining stable data of display luminance including the ambient environment were considered.

\section{Display evaluation aspects}

This chapter describes the evaluation aspects of the brightness of the display used by this research. The brightness of a display is expressed with a luminance and a contrast ratio. In addition, a viewing angle that assumes about ten people can see the display is set.

Luminance is a photometric measure of the luminous intensity per unit area of light travelling in a given direction. Where $F$ is the luminous flux or luminous power $(\mathrm{lm}), \theta$ is the angle between the surface normal and the specified direction, $A$ is the area of the surface $\left(\mathrm{m}^{2}\right)$, and $\Omega$ is the solid angle (sr), Luminance $L\left(\mathrm{~cd} / \mathrm{m}^{2}\right)$ is defined by 


$$
L=\frac{d^{2} F}{d A d \Omega \cos \theta}
$$

The contrast ratio is the luminosity ratio of the maximum luminosity $L_{\max }\{(\mathrm{R}, \mathrm{G}, \mathrm{B})=(255,255,255)\}$ and the minimum luminosity $L_{\min }\{(\mathrm{R}$, $\mathrm{G}, \mathrm{B})=(0,0,0)\}$ on a display. The higher the contrast ratio, the greater the difference between $L_{\max }$ and $L_{\min }$ is. To raise the contrast ratio, $L_{\max }$ is enlarged or $L_{\min }$ is unlimitedly brought close to 0 . Contrast ratio $C R$ is defined by

$$
C R=\frac{L_{\max }}{L_{\min }}
$$

The viewing angle is the luminosity ratio of the display front maximum luminosity $L_{f}\{(\mathrm{R}, \mathrm{G}, \mathrm{B})=(255,255,255)\}$ and the diagonal 45 display degree maximum luminosity $L_{s}\{(\mathrm{R}, \mathrm{G}, \mathrm{B})=(255,255,255)\}$. The lower the value, the smaller the difference between the luminance from the front and the diagonal luminance. That is, the screen can be seen very well from a diagonal viewpoint. Viewing angle $V A$ is defined by

$V A=\frac{L_{f}}{L_{s}}$

To grasp the characteristics of the display for outdoor use, luminance $L$ was measured in the darkroom and outdoors. The contrast ratio $C R$ and the viewing angle $V A$ were calculated based on the measured luminosity value. Display manufacturers usually provide the dark room contrast ratio $C R_{d}$ as the standard value, which is a contrast ratio usually measured in a dark room where illuminance is 0 . However, since it is significantly influenced by outdoor daylight, just the dark room contrast ratio of evaluation of an outdoor display is inadequate. Therefore, it is necessary to measure the ambient contrast ratio $C R_{o}$, which is a contrast ratio that adds the conditions of fixed outdoor daylight.

\section{Experiment and result}

\subsection{WHOLE IMAGE OF EXPERIMENT}

The procedure of the experiment is shown below:

1. The display, the luminance meter, and the illuminance meter were set up in the darkroom and outdoors as shown in Figure 2.

2. The power supply of each device was switched on.

3. Level 1 of the brightness of the display was set.

4. The position in which luminance was measured was set as the front relative to the display.

5. A black screen $\{(\mathrm{R}, \mathrm{G}, \mathrm{B})=(0,0,0)\}$, which has the lowest luminance, was displayed, and the luminance at the center of the screen was measured five times.

6. A white screen $\{(\mathrm{R}, \mathrm{G}, \mathrm{B})=(255,255,255)\}$, which has the highest luminance, was displayed, and luminance at the center of the screen was measured five times.

7. The positions in which luminance was measured were set as the diagonal 45-degree position and the 135-degree position relative to the display.
TABLE 1. Specifications of the display.

\begin{tabular}{|l|l|l|l|l|}
\hline $\begin{array}{l}\text { Display } \\
\text { name }\end{array}$ & Photo & $\begin{array}{l}\text { Weig } \\
\mathrm{ht} \\
\mathrm{kg})\end{array}$ & $\begin{array}{l}\text { Display } \\
\text { size (inch) }\end{array}$ & $\begin{array}{l}\text { Display } \\
\text { surface }\end{array}$ \\
\hline $\begin{array}{l}\text { NEC } \\
\text { Shield } \\
\text { PRO } \\
\text { FC-N22 } \\
\text { A }\end{array}$ & 2.5 & 12.1 & $\begin{array}{l}\text { Matt } \\
\text { finish }\end{array}$ \\
\hline
\end{tabular}

TABLE 2. Measurement conditions.

\begin{tabular}{|l|l|l|}
\hline & Darkroom experiment & Outdoor experiment \\
\hline $\begin{array}{l}\text { Illuminance on } \\
\text { the ground (lx) }\end{array}$ & 0 & $22,030-107,800$ \\
\hline $\begin{array}{l}\text { Measurement } \\
\text { time }\end{array}$ & $\begin{array}{l}\text { Nov. 5, at 18:30-20:30, } \\
2009\end{array}$ & $\begin{array}{l}\text { Nov. 6 at 10:44-12:35 and } \\
\text { Nov. 7 at 10:28 - 11:19, } \\
2009\end{array}$ \\
\hline Weather & Clear day & Clear day \\
\hline $\begin{array}{l}\text { Latitude, } \\
\text { Longitude }\end{array}$ & $34.822623,135.522781$ (Osaka, Japan) \\
\hline
\end{tabular}

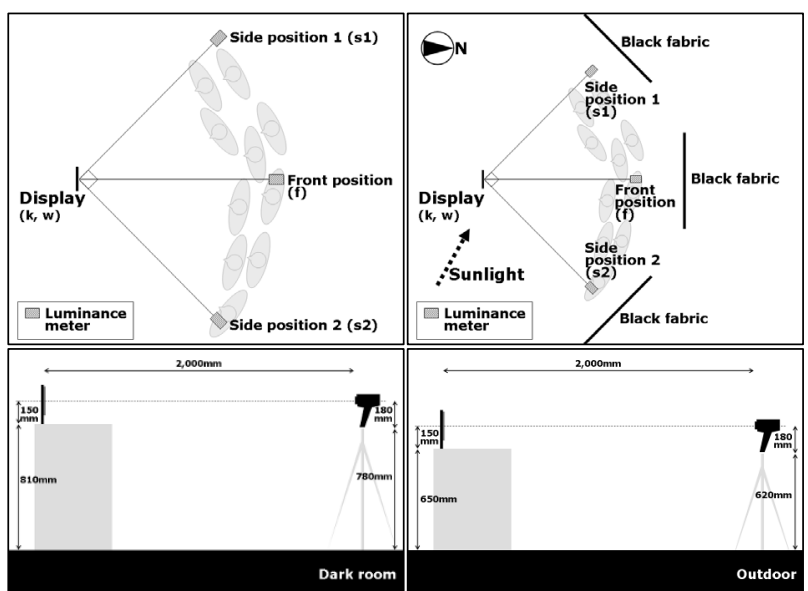

Figure 2. Plan of dark-room experiment (left) and outdoor experiment (right).

8. A white screen $\{(\mathrm{R}, \mathrm{G}, \mathrm{B})=(255,255,255)\}$, which has the highest luminance, was displayed, and luminance at the center of the screen was measured five times.

9. The level of brightness of the display was changed.

10. Each experiment was done from No.4 to No.9 repeatedly.

The related specifications of the display are shown in TABLE 1. The measurement conditions are shown in TABLE 2. Figure 2 shows the plans of the experiment. The luminance meter used was an LS-100 and the illuminance meter used was a T-10 by Konica Minolta Sensing, inc.

\subsection{RESULT OF DARKROOM EXPERIMENT}

The measurement was carried out five times for each brightness level. The mean value of the value obtained for the five measurements was used for the analysis. When the screen was black, the value of the screen luminance $L_{k}$ on each step indicated from 0.002 to $0.869 \mathrm{~cd} / \mathrm{m}^{2}$ as shown in Figure 3. No value was exactly 0 . This is because it is difficult to completely remove the influence of the LED backlight from the screen since it forms a basic part of the principle of operation of the LCD (liquid crystal display). When the screen is white, the value of the screen 
luminance $L_{w}$ of each step indicated from 0.3 to $663.5 \mathrm{~cd} / \mathrm{m}^{2}$. The maximum luminance was $750 \mathrm{~cd} / \mathrm{m}^{2}$ according to the specifications provided by the display manufacturer. However, it is thought that a sufficient value was obtained for the measurement from a position $2 \mathrm{~m}$ away in this experiment. The contrast ratio $C R$ was indicated from 157.0 to 779.5 as shown in Figure 4. The viewing angle of the display $V A$ was indicated from 4.166 to 4.240 as shown in Figure 5.

\subsection{RESULT OF OUTDOOR EXPERIMENT}

When experimenting outdoors, where the parameters fluctuated greatly, the experiment was executed according to the following conditions based on the result of the presented research to obtain a more stable value ${ }^{8)}$.

1. The change in the illuminance was noted. Outdoors, the influence of sunlight on the display is considerable. Moreover, the experiment takes about two hours. Therefore, the change in sunlight was recorded by measuring the illuminance on the ground.

2. The display was set up with the sun behind it. The influence of direct light of the sun is considerable. Therefore, the display was measured against the light to reduce the influence of the sun.

3. A black fabric was used for the background reflected on the display. The influence of the ambient environment on the display is large. Many aspects are reflected in the display when the color in the ambient environment is white. Therefore, a black fabric was used for the ambient environment to reduce reflections on the surface of the display.

(1) Result of illuminance of sunlight on the ground

The illuminance of sunlight on the ground was measured in this experiment. In regard to the experiment time, the illuminance was measured for 1 hour and 50 minutes. Figure 6 clearly shows that illuminance outdoors was not constant. On Nov. 6, the illuminance meter indicated from 67,300 to $72,8001 x$. On Nov. 7 , the illuminance meter indicated from 67,300 to $73,5001 x$. However, because the experiment day was fine weather, the degree of change of this illuminance was considerably less than that in the presented research ${ }^{8)}$.

(2) Result of measurement of display luminance outdoors

Figure 7 shows the luminance of each step and the illuminance of the ground. When the display was set to a black screen, the luminance indicated from 320.96 to $343.66 \mathrm{~cd} / \mathrm{m}^{2}$. All the values were considerably higher than that of the darkroom. It is thought that the outside light influenced this. When the display was set to a white screen, the luminance indicated from 373.96 to $1018 \mathrm{~cd} / \mathrm{m}^{2}$ with each step. All the values were considerably higher than that of the darkroom. It is thought that the outside light influenced this.

The ambient contrast ratio $C R_{o}$ of all displays indicated from 1.13 to 3.06 as shown in Figure 8. The viewing angle $V A_{o}$ of all displays indicated from 1.08 to 1.9 as shown in Figure 9.

\section{Considerations for obtaining stable data in an ambient environment}

In Chapter 3, the luminance $L$, contrast ratio $C R$ and viewing angle $V A$ of each step on the display were measured in the darkroom and outdoors.

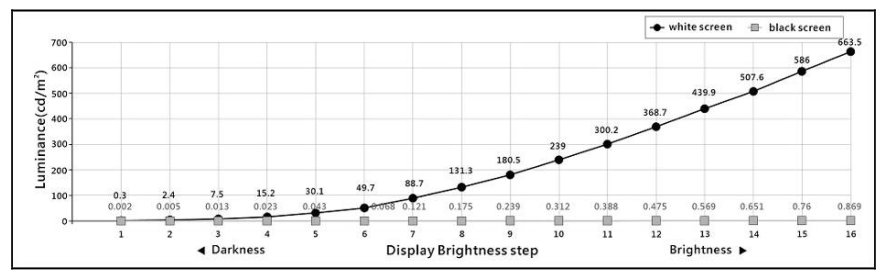

Figure 3. Dark-room luminance $\left(L_{d}\right)$ comparison of each step.

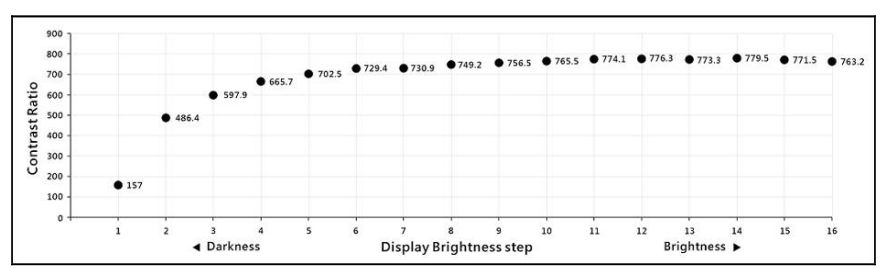

Figure 4. Dark-room contrast ratio $\left(C R_{d}\right)$ comparison of each step.

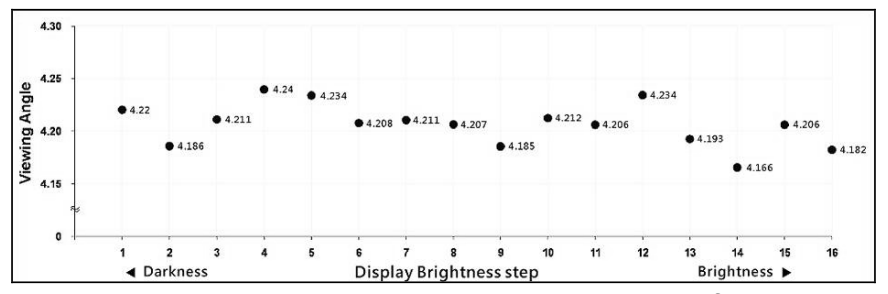

Figure 5. Dark-room viewing angle $\left(V A_{d}\right)$ comparison of each step.

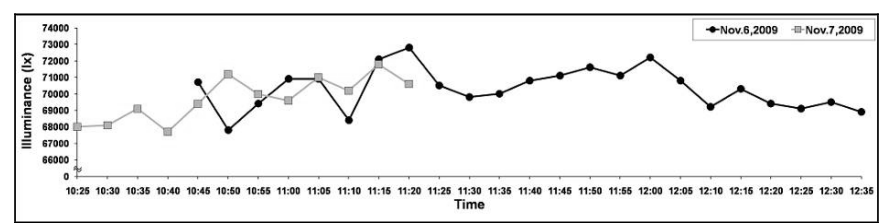

Figure 6. Illuminance change outdoors.

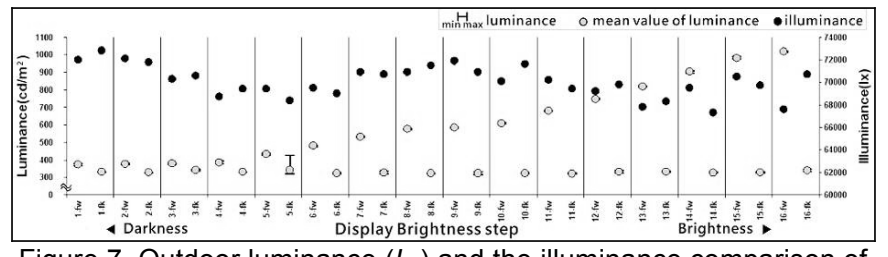

Figure 7. Outdoor luminance $\left(L_{o}\right)$ and the illuminance comparison of each step (-fk: black screen; -fw: white screen).

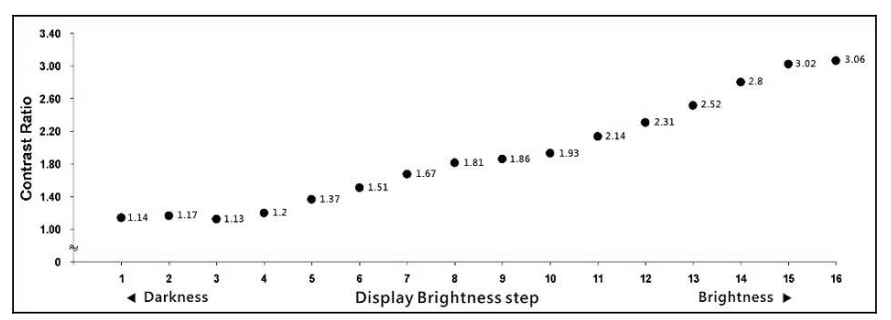

Figure 8. Ambient contrast ratio $\left(C R_{0}\right)$ comparison of each step.

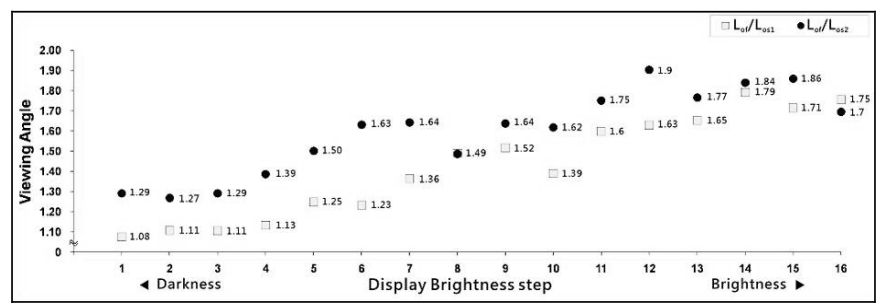

Figure 9. Outdoor viewing angle $\left(V A_{0}\right)$ comparison of each step. 
One of the main goals of this research is to manufacture a display whose contents can be seen outdoors. On the other hand, another goal is to consider how to obtain more stable luminance data on the display outdoors.

Outdoors, the luminance of the display is greatly influenced by sunlight and the ambient environment. It is difficult to obtain a value of constant brightness of the display and an ambient contrast when measuring outdoors because these factors always change.

Methods for stably obtaining the value are as follows. The first is a method of constructing a pilot machine that measures the luminance of the display in the laboratory. This method measures the luminance of the display while irradiating constant outside light to the measured display. Therefore, it is possible to measure the brightness of the display of the machine. A problem is that because it uses artificial lighting to represent outside light, it is difficult to obtain the large quantity of light provided by sunlight.

The second is a method using computer simulation. It is also possible to use and to simulate large quantities of light like sunlight by reproducing the experimental environment on the computer. The simulation result is verified by comparing the measurement data shown in Chapter 3 with the result of the simulation. The problem is to strictly set parameters of the position of sunlight, quantities of sunlight, physical properties of the surface of the display, and physical properties in the ambient environment, etc (Figure 10).

\section{Conclusion and future work}

The results achieved in the present study are as follows:

- The outdoor use of digital tools such as AR or MR is anticipated but there is a problem that the screen is hard to see when a normal PC display is used. To clarify the reason for this, luminance, the contrast ratio, and the viewing angle of a display designed for outdoor use were evaluated and measured according to each step of 16 luminance settings in the darkroom to obtain the basic data.

- To decrease the variation factors outdoors, the display was set up with the sun behind it and black fabric was used for the background reflected on the display. The luminance, the ambient contrast ratio, and the viewing angle of the display were measured outdoors according to each of 16 luminance settings to obtain the basic data. The change in the illuminance was also noted.

- Two methods of stably obtaining the values were considered. The first was constructing a pilot machine to measure the ambient luminance of the display in the laboratory. The second was a computer simulation. The features and problems of each method were also described.

Future works are required to verify the method of stably obtaining the values described in Chapter 4 concretely.

\section{Acknowledgement}

The author would like to thank Mr. Wei Cheng Lin and Mr. Tian Zhang who are research students of Osaka University for supporting these

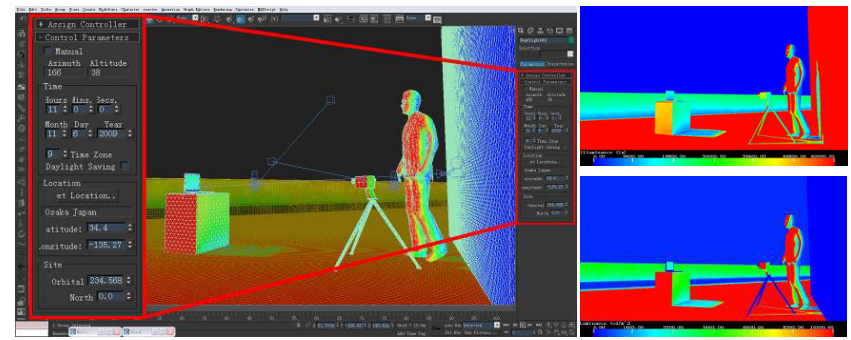

Figure 10. Example of computer simulation. Parameter setting (left); Results of illuminance (upper right) and luminance (lower right).

experiments.

\section{References}

1. Behringer, R. et al.: A Wearable Augmented Reality Test-bed for Navigation and Control, Built Solely with Commercial-off-the-Shelf (COTS) Hardware, Proc. 2nd Int'l Symp. Augmented Reality 2000 (ISAR 00), IEEE CS Press, Los Alamitos, Galif., 12-19, 2000

2. Feiner, S., MacIntyre, B., Höllerer, T., Webster, A.: A touring machine: Prototyping 3D mobile augmented reality systems for exploring the urban environment, Personal and Ubiquitous Computing, Volume 1, Number 4, Springer London, 208-217, 1997

3. Julier, S. er al.: Information Filtering for Mobile Augmented Reality, Proc. Int'l Symp. Augmented Reality 2000 (ISAR 00), IEEE CS Press, Los Alamitos, Calif., $3-11,2000$

4. Kaga, A., Kawaguchi, M., Fukuda, T., Yeo, W.H.: Simulation of an Historic Building Using a Tablet MR System, Proceedings of the 12th International Conference on Computer Aided Architectural Design Futures, Sydney (Australia), 45-58, 2007

5. Kuo, C.G., Lin, H.C., Shen, Y.T., Jeng, T.S.: Mobile Augmented Reality for Spatial Information Exploration, Proceedings of the 9th International Conference on Computer Aided Architectural Design Research in Asia (CAADRIA2004), 891-900, 2004

6. Yabuki, N., Miyashita, K., Fukuda, T.: Evaluation of Invisible Height for Landscape Preservation Using Augmented Reality, Proceedings of the 9th International Conference on Construction Applications of Virtual Reality (conVR) 2009, 495-502, 2009

7. Fukuda, T.: Analysis of a Mixed Reality Display for Outdoor and Multi-user Implementation, 4th ASCAAD Conference (Arab Society for Computer Aided Architectural Design), 323-334, 2009

8. Fukuda, T.: Analysis of Display Luminance for Outdoor and Multi-user use, Proceedings of the 9th International Conference on Construction Applications of Virtual Reality (conVR) 2009, 49-58, 2009

9. “NEC Corporation": Factory Computer FC-NOTE Series Shield PRO N22A $<$ http://www.nec.co.id/files/brochures/NEC\%20Shield\%20Pro\%20Brochure.pd f> (accessed 10 November 2009).

[2010 年 2 月 18 日原稿受理 2010 年 6 月 15 日採用決定］ 